Editorial note: Last week Nature published an Editorial on historical injustice in science and how it is marked by statues and other memorials (Nature 549, 5-6; 2017). Many readers criticized its wording, position and tone (see Nature http://doi.org/ccvm; 2017). Nature apologises for the original article and has now issued a correction. Nature's editors continue to discuss the issues raised and welcome further feedback (go.nature. com/cmchno).

\section{Statues: a mother of gynaecology}

I have often walked past the statue of J. Marion Sims (see Nature 549, 5-6; 2017). It seems to say to me: "Go away, woman. You have no authority here," and: "Go away, woman of African descent. You cannot have the intellect to contribute to the science of your own health care."

Sims' statue stands across the street from the New York Academy of Medicine, which houses a handwritten book from the thirteenth century. This includes several texts on women's medicine that challenge your characterization of Sims as "the father of modern gynaecology". One derives from the work of a woman in the twelfth century, Trota of Salerno, who wrote about treatments for women: some 700 years before Sims, she described the surgical repair of obstetrical fistulae.

In 1881, the physician Marie E. Zakrzewska, a contemporary of Sims, questioned whether there would ever be a monument to pioneering women physicians. She said, "We need such landmarks of civilization not because those who died have lived for fame, no, but because the nowliving, as well as those who will live long afterward, need encouragement for utilizing their capabilities."

The statue of Sims only encouraged me to ask, which your Editorial does not, why the field of women's medicine has a father but no mother.

Monica H. Green Arizona State University, Tempe, Arizona, USA. monica.green@asu.edu

\section{Statues: learn from mistakes}

I am disheartened that Nature has apparently joined the chorus of tone-deaf statements on race and racism in science, technology, engineering and mathematics (see Nature 549, 5-6; 2017). Your unsigned article may have done real damage to science and to marginalized minority scientists who need the support of the institutions of power. It is white privilege at its height.

I hope you will institute a set of policies to ensure that racially charged pieces, such as this "whitewashing" one, go through a more thorough review process (ideally by scientists of colour) before publishing them.

It is critically important not to erase your mis-step, which, uncorrected, stood as a clear example of institutionalized racism. If we are to move to a more mature phase of equity, you need to learn from it and prevent its repeat.

Kim M. Cobb Georgia Institute of Technology, Atlanta, Georgia, USA.

kcobb@gatech.edu

\section{Statues: for those deserving respect}

We should reserve statuaries for people who deserve our respect - not just for their discoveries, but also for their methods (Nature 549, 5-6; 2017). Sims' discoveries will not be forgotten. Sims himself will remain an enduring example of appalling scientific ethics.
It is not the removal of statues that 'whitewashes' history, but the placing of those statues. Statues of scientists whose research was cruel, unethical and inhumane signal that the accomplishments of a white man are more important than his methods or the countless people he victimized. Sims was one such scientist who was deemed so important that his heinous treatment of enslaved black women was considered irrelevant. White has been washed over black.

Scientists have a responsibility to demonstrate that such research methods are not acceptable. Statues of the perpetrators should be replaced by monuments to those research subjects whose sacrifices led to important scientific discoveries, and by new statues commemorating scientists from underrepresented minorities whose work is so often overlooked.

Katherine E. Gould Pasadena City College, Pasadena, California, USA. kgould2@pasadena.edu

\section{Don't tamper with SI-unit consistency}

I disagree with your suggestion to promote the radian to the International System of Units (SI units) to address the confusion over dimensionless numbers (Nature 548, 135; 2017). On the contrary, this could perpetrate the mistaken view that everything in the physical world has dimensions.

The humble planar angle is an example. As the ratio of the length of a swept arc to the radius of that arc, it is dimensionless. Typically, however, people append the radian label directly to the resulting number, or attach other tags - such as degrees, gradians or minutes of arc having used other conversion factors.

You mention the regrettable practice of referring to torque units in joules per radian. The mathematical distinction between torque and energy is clear: torque is the vector product of the radial 'lever arm' and the applied force. Its units are strictly newton metres. Joules are applied only if this torque moves through a unitless vector rotation, with the scalar product yielding the scalar quantity of energy.

If the radian were to be promoted to an SI unit, a further point of caution is that formal dimensionless analysis would require ad hoc patching because of unbalanced numbers of terms containing the radian label. This is especially the case for established dimensionless groups that have angular frequency components (such as the Strouhal, Rossby and Womersley numbers).

In my view, the clear teaching of principles is more important than unwarranted tinkering with the consistency of the SI system.

Otherwise, we risk throwing the dimensionless baby out with the unit-ambiguous bathwater.

Michael C. Wendl Washington University, St Louis, Missouri, USA.

mwendl@wustl.edu

CONTRIBUTIONS

Correspondence may be sent to correspondence@ nature.com after consulting the author guidelines at http://go.nature.com/ cmchno.

\section{CORRECTION}

The Nature Index

article 'Game changers'

(Nature 548, S9-S11; 2017)

gave the wrong affiliation

for David Lipman. He was at the US National Institute of Arthritis, Diabetes, and

Digestive and Kidney Diseases. 